\title{
MODEL KESUKSESAN \\ SISTEM INFORMASI PENGENDALIAN PEMBANGUNAN DAERAH DI BIRO ADMINISTRASI PEMBANGUNAN SEKRETARIAT DAERAH PROVINSI KEPULAUAN RIAU
}

Oleh

\author{
Dolfi Lukmansyah
}

Mahasiswa Program Pascasarjana Magister Terapan Ilmu Pemerintahan IPDN

dolfi.lukmansyah@gmail.com

\begin{abstract}
$C$ ontrol of the implementation of the development plan is intended to ensure the achievement of development goals and objectives. Monitoring activities include the implementation of programs and activities carried out on the development of realization of fund absorption, realization of achievement of output targets and constraints faced by describing the reality and dynamics of government as they are by making carefull measurements of the Model of Regional Development Control Information System Success in the Administration Bureau Construction of the Regional Secretariat of the Riau Islands Province.

The method used in this study is a qualitative research method. Informants in this study were employees who were directly related to this system. The data collection techniques used are through interviews, observation, and documentation. In this study the Development Control Information System is the choice of the author in the study.

The results of this study using De Lone and Mc Lean there is 6 dimensions of success in information technology systems and using e-government theory are then associated with development control information systems, it will be known that information systems models are useful in reporting physical and financial budget realization based on efficiency principles, right use, timely implementation and use can be accounted for.
\end{abstract}

Keywords: regional development control information system, Riau Islands Province

\footnotetext{
ABSTRAK

$\mathrm{P}^{\mathrm{e}}$ engendalian pelaksanaan rencana pembangunan dimaksudkan untuk menjamin tercapainya tujuan dan sasaran pembangunan. Kegiatan pemantauan meliputi pelaksanaan program dan kegiatan yang dilakukan terhadap perkembangan realisasi penyerapan dana, realisasi pencapaian target keluaran (output) dan kendala yang dihadapi dengan menggambarkan realita dan dinamika pemerintahan dengan apa adanya dengan melakukan pengukuran cermat terhadap Model Kesuksesan Sistem Informasi Pengendalian Pembangunan Daerah di Biro Administrasi Pembangunan Sekretariat Daerah Provinsi Kepulauan Riau.

Metode yang digunakan dalam penelitian ini adalah metode penelitian kualitatif. Informan dalam penelitian ini adalah pegawai yang berhubungan langsung dengan sistem ini. Adapun teknik pengumpulan data yang digunakan adalah melalui wawancara, observasi, dan dokumentasi. Dalam penelitian ini Sistem Informasi Pengendalian Pembangunan adalah sebagai pilihan penulis dalam pengkajiannya.
} 
Hasil Penelitian ini dengan menggunakan 6 dimensi model kesuksesan sistem teknologi informasi menurut De Lone and Mc Lean dan menggunakan teori e-government kemudian dikaitkan dengan sistem informasi pengendalian pembangunan, maka akan diketahui model sistem informasi yang berguna dalam pelaporan realisasi anggaran fisik dan keuangan berlandaskan azas efisiensi, tepat guna, tepat waktu pelaksanaan dan penggunaannya dapat dipertanggungjawabkan.

Kata kunci: sistem informasi pengendalian pembangunan daerah, Provinsi Kepulauan Riau.

\section{PENDAHULUAN}

A manat dalam Peraturan Pemerintah Nomor 39 Tahun 2006 tentang Tata Cara dan Pengendalian Pelaksanaan Rencana Pembangunan menimbang bahwa untuk melaksanakan ketentuan Pasal 30 Undang-Undang Nomor 25 tahun 2004 tentang Sistem Perencanaan Pembangunan Nasional perlu menetapkan Peraturan Pemerintah tentang tata cara pengendalian dan evaluasi pelaksanaan rencana pembangunan ${ }^{1}$. Pengendalian pelaksanaan rencana pembangunan dimaksudkan untuk menjamin tercapainya tujuan dan sasaran pembangunan. Pengendalian pelaksanaan rencana pembangunan dilakukan dengan melalui kegiatan pemantauan dan pengawasan. Peraturan Pemerintah Nomor 8 Tahun 2008 tentang Tahapan, Tata Cara Penyusunan, Pengendalian dan Evaluasi Pelaksanaan Rencana Pembangunan Daerah, menyebutkan bahwa dalam rangka pengelolaan dan pemanfaatan data dan informasi secara optimal, daerah perlu membangun sistem informasi perencanaan pembangunan daerah ${ }^{2}$.

Pelaksanaan Sistem Informasi

1 Peraturan Pemerintah, Nomor 39 Tahun 2006, tentang Tata Cara dan Pengendalian Pelaksanaan Rencana Pembangunan, Bab Menimbang.

2 Peraturan Pemerintah, Nomor 8 Tahun 2008, tentang Tahapan, Tata Cara Penyusunan, Pengendalian dan Evaluasi Pelaksanaan Rencana Pembangunan Daerah, Bab V, Pasal 30 , Ayat 1-3.
Pengendalian Pembangunan dan monitoring, dalam pelaksanaannya disesuaikan dengan rencana yang telah ditetapkan sebelumnya. Semua sistem dan teknik pengawasan menggambarkan/menyesuaikan rencana sebagai pedoman. Sistem pengawasan dimaksudkan untuk membantu pimpinan dalam melaksanakan pengawasannya. Di samping itu, laporan pengendalian pembangunan menunjukkan penyimpanganpenyimpangan pada hal-hal yang penting. Demi mewujudkan transparansi dan akuntabilitas penyelenggaraan pembangunan daerah dan sebagai bahan untuk melakukan monitoring terhadap pelaksanaan kegiatan yang dilakukan oleh Pemerintah Daerah, maka dibuatlah suatu Sistem Pelaporan Pengendalian Pembangunan yang berbasis internet (web based), dengan tujuan untuk mempermudah dalam melakukan kegiatan monitoring kemajuan pelaksanaan progres realisasi fisik dan keuangan kegiatan pembangunan di lingkungan Pemerintah Provinsi Kepulauan Riau.

\section{MASALAH PENELITIAN}

1. Bagaimanakah Model Kesuksesan Sistem Informasi Pengendalian Pembangunan Daerah di Biro Administrasi Pembangunan Sekretariat Daerah Provinsi Kepulauan Riau.

2. Apa sajakah faktor pendukung dan penghambat Model Kesuksesan Sistem Informasi Pengendalian Pembangunan Daerah di Biro Administrasi Pembangunan Sekretariat Daerah Provinsi Kepulauan Riau. 
3. Apa sajakah upaya mengatasi faktor penghambat Model Kesuksesan Sistem Informasi Pengendalian Pembangunan Daerah di Biro Administrasi Pembangunan Sekretariat Daerah Provinsi Kepulauan Riau.

\section{KERANGKA PEMIKIRAN}

Dalam pelaksanaan penelitian kualitatif ini penulis harus membuat suatu bentuk kerangka pemikiran sebagai dasar acuan dalam pengembangan berbagai teori serta landasan normatif guna menyelesaikan permasalahan dalam penelitian menjadi lebih terarah dan sistematis.

\section{TINJAUAN PUSTAKA}

\section{MODEL KeSUKSESAN SISTEM INFORMASI}

Model kesuksesan sistem informasi yang dikembangkan oleh DeLone dan McLean (D\&M IS success Model) dalam Jogiyanto adalah model yang sederhana dan dianggap cukup valid, sebab dibutuhkan suatu model sebagai acuan untuk membuat sistem teknologi informasi yang dapat diterapkan secara sukses di organisasi. Model kesuksesan ini didasarkan pada proses dan hubungan kausal dari dimensidimensi di model.

Model tersebut tidak mengukur keenam dimensi pengukuran kesuksesan sistem informasi secara independent, tetapi mengukurnya secara keseluruhan satu memengaruhi yang lainnya.

\section{FAKTOR PENDUKUng}

Ada tiga elemen sukses pengembangan e-government yang harus dimiliki dan diperhatikan sungguh-sungguh. Masingmasing sukses tersebut adalah:

1. Support (dukungan);

Dialokasikannya sejumlah sumber daya (manusia, finansial, tenaga, waktu, informasi, dan lain-lain) di setiap tataran pemerintah untuk membangun semangat lintas sektoral;

2. Capacity (kapasitas);

Ketersediaan sumber daya dan infrastruktur teknologi yang cukup untuk melaksanakan berbagai inisiatif e-Government, terutama yang berkaitan dengan sumber daya finansial;

3. Value (Manfaat).

Guna menentukan besar tidaknya manfaat yang diperoleh dengan adanya e-government bukanlah kalangan pemerintah sendiri, melainkan masyarakat dan mereka yang berkepentingan (demand side). Untuk itulah pemerintah harus benar-benar teliti dalam memilih prioritas jenis aplikasi e-government apa saja yang harus didahulukan pembangunannya agar benar-benar memberikan value (manfaat) yang secara signifikan dirasakan oleh masyarakatnya ${ }^{3}$.

Mengukur faktor penghambat dengan menggunakan aspek architecture ${ }^{4}$ yang berhubungan dengan arsitektur sistem dan teknologi informasi yang dimiliki saat ini oleh pemerintah yang mana harus benarbenar diperhatikan, yaitu:

\section{Business Model.}

Berkaitan dengan seberapa jauh pemerintah telah berhasi memetakan seluruh proses pelayanan (business process) yang ada;

2. Security.

Berkaitan dengan penerapan sistem keamanan e-government untuk meningkatkan kepercayaan masyarakat dan pihak lain yang berkepentingan;

3 Richardus Eko Indrajit, "Electronic Government Modul Pembelajaran Berbasis Standar Kompetensi dan Kualifikasi Kerja”, (Yogyakarta: Preinexus, 2016), hlm. 11.

4 KPMG dalam Richardus Eko Indrajit, Ibid, Hlm. 84-85. 


\section{Data.}

Berkaitan dengan telah dipetakannya seluruh kebutuhan data dan relasinya (data model) yang perlu dikelola di dalam e-government.

4. Application.

Berkaitan dengan usaha mendefinisikan dan menerapkan beragam aplikasi dan perangkat lunak (software) di dalam setiap inisiatif e-government.

5. Technolgy.

Berkaitan dengan telah ditentukannya standar spesifikasi pemakaian perangkat keras (hardware).

6. Network.

Berkaitan dengan telah didefinisikan dan ditentukan standar komunikasi informasi melalui infrastruktur jaringan.

Upaya dalam mengatasi faktor penghambat dengan menggunakan performance management ${ }^{5}$ yang berhubungan dengan kemampuan pemerintah dalam menentukan dan mengukur tingkat keberhasilan pelaksanaan program e-government yang ada. Secara prinsip ada lima hal yang perlu benar-benar dikaji, masing-masing adalah sebagai berikut.

1. Client satisfaction.

Berkaitan dengan dimilikinya mekanisme oleh pemerintah untuk mengukur efektivitas pelayanan e-government;

2. Privacy Complience.

Berkaitan dengan adanya penjaminan terhadap hak-hak privasi (kerahasiaan) seseorang atau sekelompok orang yang harus dilindungi;

3. Benefits Monitoring.

Berkaitan dengan kemampuan pemerintah dalam melakukan

$5 \quad$ Ibid, Hlm. 87. pemantauan terhadap manfaat yang dirasakan;

4. Predictability.

Berkaitan dengan mekanisme untuk memantau dan mengukur tingkat ketersediaan teknologi informasi yang dibutuhkan (database, aplikasi, dan teknologi) untuk menjalankan sistem e-government.

\section{HASIL PENELITIAN}

MODEL KESUKSESAN SISTEM INFORMASI

Pengendalian Pembangunan Daerah

di Biro Administrasi Pembangunan

Sekretariat DaErah Provinsi

\section{KePUlauan Riau}

Terdapat enam dimensi dan ukuranukurannya, antara lain:

1. Dimensi Kualitas Sistem (System Quality) dalam ukuran Kecanggihan Sistem Informasi (Penggunaan Teknologi Baru).

Kualitas sistem informasi dalam ukuran kecanggihan sistem informasi pengendalian pembangunan telah didukung oleh sarana dan prasarana yang disediakan oleh Pemerintah Provinsi Kepulauan Riau, Kecanggihan teknologi telah dimanfaatkan untuk dapat mendorong adanya efisiensi dari sisi anggaran kerja.

2. Dimensi Kualitas Informasi (Information Quality) dalam ukuran Mudah Digunakan dan kesesuaian;

Efisiensi sangat tergantung pada kurun waktu dan teknologi. Sistem informasi yang sangat efisien saat ini belum tentu efisien beberapa tahun ke depan karena perkembangan Teknologi Infomasi Komunikasi dan demand dari stakeholders-nya dan sistem informasi pengendalian pembangunan telah dibuat berdasarkan peraturan perundangundangan yang berlaku sehingga tidak akan ditemukan lagi pelanggaran- 
pelanggaran atau improvisasi dalam pelaporan realisasi fisik dan keuangan masing-masing Organisasi Perangkat Daerah.

3. Dimensi Kepuasan Pemakai (User satisfaction) dalam ukuran Kepuasan Menyeluruh;

Sistem informasi pengendalian pembangunan telah memenuhi berbagai syarat dari segi kecanggihan, keamanan data, dan sebagai media untuk mempermudah pemerintah dalam pengambilan kebijakan dalam pengelolaan kegiatan pembangunan melalui outputyang dihasilkan dari sistem informasi pengendalian pembangunan yakni realisasi fisik dan keuangannya.

4. Dimensi Penggunaan Informasi (Information Use) dalam ukuran Penggunaan Sistem Informasi Untuk Mendukung Produksi.

Sistem informasi pengendalian pembangunan ini dapat menampilkan secara langsung hasil atau report dari realisasi anggaran dan fisik masingmasing Organisasi Perangkat Daerah dan kemudian dibuatlah suatu report atau laporan berupa sebuah progres, progres tersebut menjadi dasar apakah masingmasing Organisasi Perangkat Daerah telah memenuhi target ataukah masih jauh dari target yang telah ditetapkan.

5. Dimensi Dampak Individual (Individual Impact) dalam ukuran Efesiensi dan Efektivitas Pengambilan Keputusan.

Sistem informasi pengendalian pembangunan dapat menentukan kualitas perencanaan dan menciptakan suatu hasil capaian tujuan yaitu efesiensi pengeluaran dalam kegiatan monitoring, peningkatan dari realisasi fisik dan keuangan kegiatan pembangunan. sistem informasi pengendalian pembangunan telah membuat kinerja pemerintah menjadi meningkat.
6. Dimensi Dampak Organisasi (Organization Impact) dalam ukuran Efektivitas Organisasional

Melalui pemanfaatkan integrasi data pada sistem informasi pengendalian pembangunan maka progres realisasi fisik dan keuangan kegiatan pembangunan dapat berjalan dengan lebih efisien, cepat dan meminimalisir kesalahan komunikasi data pada sistem kerja yang dahulunya masih manual.

\section{FAKTOR PENDUKUng}

1. Support

Pemerintah Provinsi Kepulauan Riau melalui Biro Administrasi Pembangunan telah mengalokasikan dana dan menetapkan strategi terhadap penguatan dalam sistem informasi pengendalian pembangunan dengan cara memadukan sistem penyelenggaraan pemerintah melalui jaringan sistem informasi on-line antar- instansi pemerintah baik pusat dan daerah untuk mengakses seluruh data dan informasi terutama yang berhubungan dengan kegiatan pembangunan di lingkungan Pemerintah Provinsi Kepulauan Riau.

2. Capacity

Pemanfaatan teknologi informasi pada pemerintahan bertujuan untuk mendukung penyelenggaraan tata kelola organisasi yang lebih baik, sehingga mampu menyediakan layanan informasi tepat guna bagi stakeholders dalam menciptakan efisiensi dari segi pembangunan, sehingga hal-hal yang dihasilkan semakin kompetitif.

3. Value

$\begin{array}{llr}\text { Sistem informasi } & \text { Pengendalian } \\ \text { Pembangunan telah } & \text { terintegrasi } \\ \text { dengan sistem } & \text { web (online) guna }\end{array}$ 
proses sinkronisasi data secara online yang akan memberikan Kemudahan, kecepatan dan fleksibilitas dalam pengolahan data-datanya. Sehingga, hal tersebut sangat menguntungkan karena memudahkan dalam berbagai proses data yang dahulunya dilakukan secara manual.

\section{FAKToR PENGHAMbat}

\section{Business Model}

Kekurangan dari sistem informasi pengendalian pembangunan yang masih diperlukan adanya perbaikan-perbaikan dan pembaharuan. Masih ditemukannya keterlambatan laporan dari organisasi perangkat daerah dalam melaporkan hasil penyerapan anggaran realisasi fisik dan keuangannya.

\section{Security and Data}

Penilaian kinerja sistem informasi berfokus pada pertimbangan dari keberhasilan dan kegagalan sistem informasi. Masalah kegagalan sistem informasi dapat dianalisis dengan mengasumsikan bahwa belajar dari kegagalan sistem informasi akan memberikan pelajaran penting untuk merumuskan strategi sukses bagi perencanaan, pengembangan, pelaksanaan, dan pengelolaan sistem informasi pengendalian pembangunan ke depannya.

3. Application, Technolgy and Network

Sistem informasi pengendalian pembangunan dapat memonitoring seluruh kegiatan berjalan maupun yang sedang dalam tahap akan dilaksanakan, pelaporan progres atau regres keuangan dan fisik, dengan syarat data sebelumnya telah di input dan data yang dihasilkan telah sesuai dengan bentuk format yang telah ditentukan oleh peraturan perundang-undangan.

\section{UPAYA MENGATASI FAKTOR-FAKTOR}

\section{Penghambat}

1. Client Satisfaction;

Keberhasilan dalam memecahkan permasalahan penyerapan anggaran belanja dari Oganisasi Perangkat Daerah yang ada di lingkungan Provinsi Kepulauan Riau, dapat dijadikan sebagai pedoman masukan perbaikan bagi penyerapan anggaran belanja secara keseluruhan. Salah satu prinsip penganggaran adalah berbasis kinerja, yaitu penyusunan anggaran yang didasarkan pada target kinerja yang ditetapkan terlebih dahulu.

2. Privacy Complience;

Kebebasan untuk mendapatkan informasi dapat membantu memberikan pilihan langkah yang jelas bagi pemerintah dalam mengambil suatu kebijakan secara strategis. Selain itu, keterbukaan informasi publik menjadi salah satu indikator dalam mewujudkan tata kelola pemerintahan yang baik (good governance) yang yang transparan dan akuntabel.

3. Benefits Monitoring;

Pengukuran kinerja dilakukan dengan menggunakan indikator kinerja pada level sasaran dan kegiatan. Pengukuran dengan menggunakan indikator kinerja pada level sasaran digunakan untuk menunjukkan secara langsung kaitan antara sasaran dengan indikator kinerjanya, sehingga keberhasilan sasaran berdasarkan rencana kinerja tahunan yang ditetapkan dapat dilihat dengan jelas. Selain itu untuk memberikan penilaian yang lebih independen melalui indikator-indikator outcomes atau minimal outputs dari kegiatan yang terkait langsung dengan sasaran yang diinginkan. 


\section{Predictability}

Sistem informasi sangat diperlukan dalam kemajuan dan pengembangan sistem pengolahan data, agar data yang diolah dapat menjadi informasi yang berkualitas sehingga dapat digunakan sebagai alat bantu yang mendukung pengambilan keputusan juga koordinasi.

\section{SIMPULAN DAN SARAN}

\section{SIMPULAN}

Berdasarkan hasil pembahasan yang telah dibahas pada bab sebelumnya tersebut, maka dapat ditarik simpulan sebagai berikut.

1. Sistem Informasi Pengendalian pembangunan dikhususkan terhadap realisasi fisik dan keuangan kegiatan pembangunan yang dituangkan dalam dokumen perencanaan, untuk dikembangkan lebih bermanfaat bagi manajemen pembangunan. Penyempurnaan mekanisme dan pelaporan kegiatan pembangunan, secara langsung terpenuhinya dokumen resapan anggaran yang berkualitas dan dapat dievaluasi.

2. Sistem informasi pengendalian pembangunan merupakan upaya untuk mengefektifkan dan mengefisienkan pelaporan menuju pada peningkatan kualitas dengan melakukan penyederhanaan terhadap format, aplikasi dan mekanisme pelaporan kinerja pembangunan Pengaruh terhadap organisasi dapat diartikan dengan menggunakan suatu sistem informasi maka kinerja dari pemerintah akan meningkat karena itu merupakan tujuan utama dibuatnya sistem ini.

3. Penyusunan data dan informasi pembangunan daerah selama ini telah dilaksanakan dengan berbagai kegiatan, namun masih perlu untuk lebih dimantapkan dan ditingkatkan guna mengakomodasi perkembangan kemajuan di bidang teknologi data dan informasi yang berkembang di lingkungan Pemerintah Provinsi Kepulauan Riau.

\section{SARAN}

Berdasarkan hasil simpulan yang penulis telah jelaskan, maka dapat dirumuskan saran-saran yang kiranya dapat membantu untuk memperlancar jalannya proses pelaksanaan sistem informasi pembangunan dan monitoring dalam progres pembangunan di Biro Administrasi Pembangunan Sekretariat Daerah Provinsi Kepulauan Riau, antara lain:

1) Saran Teoretis

Kesuksesan sistem informasi diukur melalui kepuasan penggunanya maka biro administrasi pembangunan perlu mengonsentrasikan pengembangan sistem informasi ke kualitas informasi yang dihasilkan oleh SIPP sehingga kualitas informasi yang dihasilkan semakin tinggi agar kepuasan pengguna meningkat.

2) Saran Praktis.

a. Mengembangkan Aplikasi Sistem Informasi Pengendalian Pembangunan dan selalu melakukan update, sehingga memudahkan untuk melakukan evaluasi terhadap pelaksanaan pembangunan (real time data) dan sebagai bahan untuk pengambilan keputusan pimpinan.

b. Menambahkan fitur Guest atau tamu pada form login sehingga dapat dicapainya suatu keterbukaan informasi dan transparansi terhadap jalannya suatu progres fisik dan keuangan di lingkungan Pemerintah Provinsi Kepulauan Riau. 


\section{DAFTAR PUSTAKA}

Adisasmita, Rahardjo, 2011, Pengelolaan Pendapatan dan Anggaran Daerah, Graha Ilmu, Yogyakarta.

Arenawati, 2016, Administrasi Pemerintahan Daerah, Graha Ilmu, Yogyakarta,

Creswell, John W, 2016, Research Design, Pustaka Pelajar, Yogyakarta.

Effendy, Onong Uchjana. 1989. Sistem Informasi Manajemen. Bandung: Sinar Baru.

Eko Indrajit, Richardus, 2016, Electronic Government, Preinexus, Yogyakarta.

Hamalik, Oemar. 1995. Pengelolaan Sistem Informasi. Bandung: PT. Tri Genda Karya.

Indrajit, Richardus Eko, 2016, Electronic Government Modul Pembelajaran Berbasis Standar Kompetensi dan Kualifikasi Kerja, Preinexus, Yogyakarta.
Jogiyanto. 1991. Analisis dan Desain Sistem Informasi. Yogyakarta: Andi.

Jogiyanto. 2007. Model Kesuksesan Sistem Teknologi Informasi. Yogyakarta: Andi.

Kadir, Abdul, 2003, Pengenalan Sistem Informasi, Andi, Yogyakarta.

Rosyadi, Slamet, 2010, Paradigma Baru Manajemen Pembangunan, Gava Media, Yogyakarta.

Sedarmayanti, 2012, Good Governance "Kepemerintahan Yang Baik Bagian Kedua Edisi Revisi", Mandar Maju, Bandung.

Syaodih, Ernady, 2015, Manajemen Pembangunan Kabupaten dan Kota, Refika Aditama, Bandung. 